\title{
Potential and limitations of finite element modelling in assessing structural integrity of coralline algae under future global change
}

\author{
L. A. Melbourne ${ }^{1,2,3}$, J. Griffin ${ }^{1}$, D. N. Schmidt ${ }^{1}$, and E. J. Rayfield ${ }^{2}$ \\ ${ }^{1}$ School of Earth Sciences, University of Bristol, Wills Memorial Building, Queen's Road, BS8 1RJ, Bristol, UK \\ ${ }^{2}$ School of Earth Sciences, University of Bristol, Life Sciences Building, 24 Tyndall Avenue, BS8 1TQ, Bristol, UK \\ ${ }^{3}$ Department of Life Sciences, Natural History Museum, Cromwell Road, SW7 5BD, London, UK
}

Correspondence to: L. A. Melbourne (l.melbourne@bristol.ac.uk)

Received: 9 January 2015 - Published in Biogeosciences Discuss.: 27 February 2015

Revised: 30 September 2015 - Accepted: 2 October 2015 - Published: 14 October 2015

\begin{abstract}
Coralline algae are important habitat formers found on all rocky shores. While the impact of future ocean acidification on the physiological performance of the species has been well studied, little research has focused on potential changes in structural integrity in response to climate change. A previous study using 2-D Finite Element Analysis (FEA) suggested increased vulnerability to fracture (by wave action or boring) in algae grown under high $\mathrm{CO}_{2}$ conditions. To assess how realistically 2-D simplified models represent structural performance, a series of increasingly biologically accurate 3-D FE models that represent different aspects of coralline algal growth were developed. Simplified geometric 3-D models of the genus Lithothamnion were compared to models created from computed tomography (CT) scan data of the same genus. The biologically accurate model and the simplified geometric model representing individual cells had similar average stresses and stress distributions, emphasising the importance of the cell walls in dissipating the stress throughout the structure. In contrast models without the accurate representation of the cell geometry resulted in larger stress and strain results. Our more complex 3-D model reiterated the potential of climate change to diminish the structural integrity of the organism. This suggests that under future environmental conditions the weakening of the coralline algal skeleton along with increased external pressures (wave and bioerosion) may negatively influence the ability for coralline algae to maintain a habitat able to sustain high levels of biodiversity.
\end{abstract}

\section{Introduction}

Since the pre-industrial era $\mathrm{CO}_{2}$ concentrations have risen by more than $100 \mathrm{ppm}$ (Ciais et al., 2013). The ocean has absorbed approximately $30 \%$ of the total anthropogenic $\mathrm{CO}_{2}$ emissions (Rhein et al., 2013). This has led to a change in the carbonate chemistry of the ocean, resulting in a lowering of the carbonate saturation state and a decrease in ocean $\mathrm{pH}$, a process termed "ocean acidification" (Caldeira and Wickett, 2003). Future projections suggest an additional average decrease in $\mathrm{pH}$ of between 0.13 (RCP 2.6) and 0.42 units (RCP 8.5) by the year 2100 (Pörtner et al., 2014). Calcifying organisms are at risk as the lower carbonate saturation state may affect the ability to calcify shells and skeletons (Diaz-Pulido et al., 2011; Fabricius et al., 2011; Kroeker et al., 2010). In response, ecosystem shifts are predicted to occur; for example sea-grasses and kelps may outcompete calcifying algae as the major habitat formers in shallow water habitats (Fabricius et al., 2011).

Rhodoliths (Fig. 1), non-geniculate free living (live and dead) coralline red algae (Foster, 2001), are an extremely diverse group of benthic calcifying organisms found from the polar to the tropical regions and low intertidal zones to 150m deep (Foster, 2001). They are major contributors to the global inorganic carbon budget in shallow water ecosystems (Mackenzie et al., 2004). The largest rhodolith bed found on the Abrolhos shelf contributes roughly $5 \%$ to the global calcium carbonate budget (Amado-Filho et al., 2012). Additionally these benthic ecosystems support a high level of biodiversity by forming structurally and functionally complex habitats (Nelson, 2009) for many organisms includ- 


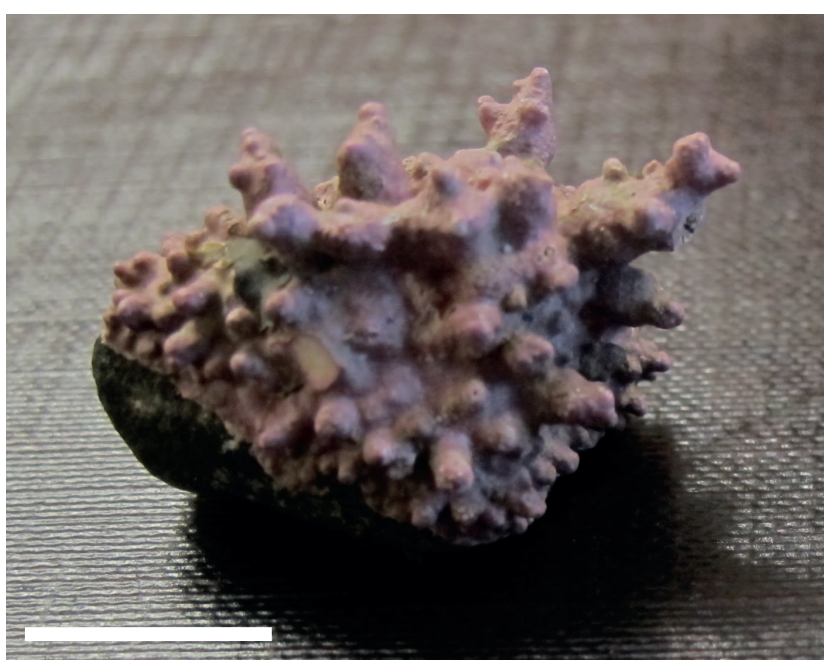

Figure 1. A Lithothamnion glaciale specimen in crustose form from Loch Creran, Oban, Scotland; Scale $=1 \mathrm{~cm}$.

ing polychaetes, crustaceans and mollusks (Foster, 2001), as well as being important nursery grounds to commercial species including scallops (Grall and Hall-Spencer, 2003). Coralline algae biodiversity and habitat complexity are directly correlated; species richness and abundance of, in particular, arthropods, annelids and cnidarians, are known to increase as rhodolith size and branching increases (Foster et al., 2013). However coralline algae are ecologically fragile due to their slow growth rate of $\sim 1 \mathrm{~mm} \mathrm{yr}^{-1}$ (Freiwald and Henrich, 1994) and sensitivity to physical disturbances such as extraction and dredging.

Furthermore, as they form high $\mathrm{Mg}$-calcite skeletons, the most soluble polymorph of calcium carbonate $\left(\mathrm{CaCO}_{3}\right.$; Andersson et al., 2008), coralline algae are more susceptible to ocean acidification than other organisms that utilise different polymorphs of calcium carbonate. Consequently, a significant loss of rhodoliths from the North Atlantic by the year 2100 has been predicted (Brodie et al., 2014). However, laboratory experiments have shown highly varied responses to elevated levels of $\mathrm{CO}_{2}$. Coralline algae (Neogoniolithon sp.) and calcareous green algae (Halimeda incrassata) exposed to increased $\mathrm{CO}_{2}$ concentrations (606 and 903 ppm for 60 days) showed an increase in calcification (Ries et al., 2009); whereas another study on Lithothamnion glaciale, a cold temperate coralline algae, displayed a decrease in growth rate at elevated $\mathrm{CO}_{2}$ conditions (589 and $755 \mu \mathrm{atm}$ for 3 months; Ragazzola et al., 2012), while also showing evidence for potential acclimation after 10 months (Ragazzola et al., 2013).

Coralline algae have many pressures to withstand in their natural environments, including wave action and bioerosion, while maintaining a structurally and functionally complex habitat. Under elevated $\mathrm{CO}_{2}$ conditions the algal skeleton appeared to be weakened (Ragazzola et al., 2012), thereby favouring erosion and breakage (Kamenos et al., 2013; Ragazzola et al., 2012).

Finite Element Analysis (FEA) is a technique that reconstructs the stress, strain and deformation in structures (Zienkiewicz et al., 2005). Originally developed for mathematical and engineering applications, it has recently become an established technique in zoology and palaeontology to understand morphology, function and evolution of hard tissue structures (Rayfield, 2007).

FEA works by transforming a continuous structure into a discrete number of elements which are connected to each other via nodes. The combination of elements and the interconnecting nodes form the mesh. Appropriate material properties (Young's modulus and Poisson's ratio) are assigned to the elements to mimic the elasticity of the structure. Adequate boundary conditions (magnitude and direction of loading and constraints) are applied and then nodal displacements are calculated in response to the applied boundary conditions and material properties of the model. The nodal displacement is used to calculate the strain and subsequently stress (using the Young's modulus, see Eq. 1) and hence mechanical performance of complex structures can be inferred. (For mathematical equations see Mathematics of FEA; Rayfield, 2007; Supplement).

$E($ Young's modulus $)=\sigma($ stress $) / \varepsilon($ Strain $)$.

Ragazzola et al. (2012) were the first to use FEA in ocean acidification studies by creating simple 2-D FE models of coralline algae to quantify the effect of elevated $\mathrm{CO}_{2}$ on the skeleton of Lithothamnion glaciale. Although the changes in growth rate were not significant, specimens grown under $\mathrm{CO}_{2}$ conditions predicted for the year 2050 were found to have significantly larger cells and thinner cell walls. These ultrastructure changes resulted in predicted increased vulnerability to fracture compared to present-day structures (Fig. 2a-b) as observed in the 2-D FE model.

These simple 2-D models represented the mechanical performance of a cross-section of uniform thickness $(1 \mu \mathrm{m}$; Ragazzola et al., 2012) through the algal structure. However, these highly innovative models were simplistic in nature. Importantly, they had not been tested to assess if they were a fair representation of skeletal mechanical performance. Consequently, the simple 2-D model may have overestimated the distribution and magnitude of stress and hence future vulnerability of algal communities. Here we have developed a set of 3-D FE geometric models to represent different aspects of coralline algae morphology and compared these models with a more biologically accurate 3-D FE model generated from computed tomography (CT) data, allowing us to assess the trade-off between computing time (Andersen and Jones, 2006; Romeed et al., 2006) and the need for an appropriate representation of the structure.

We then used our improved understanding of the performance of the 3-D models to re-assess the impact of current and future ppm $\mathrm{CO}_{2}$ induced changes to morphology on the 
$422 \mu \mathrm{atm}$
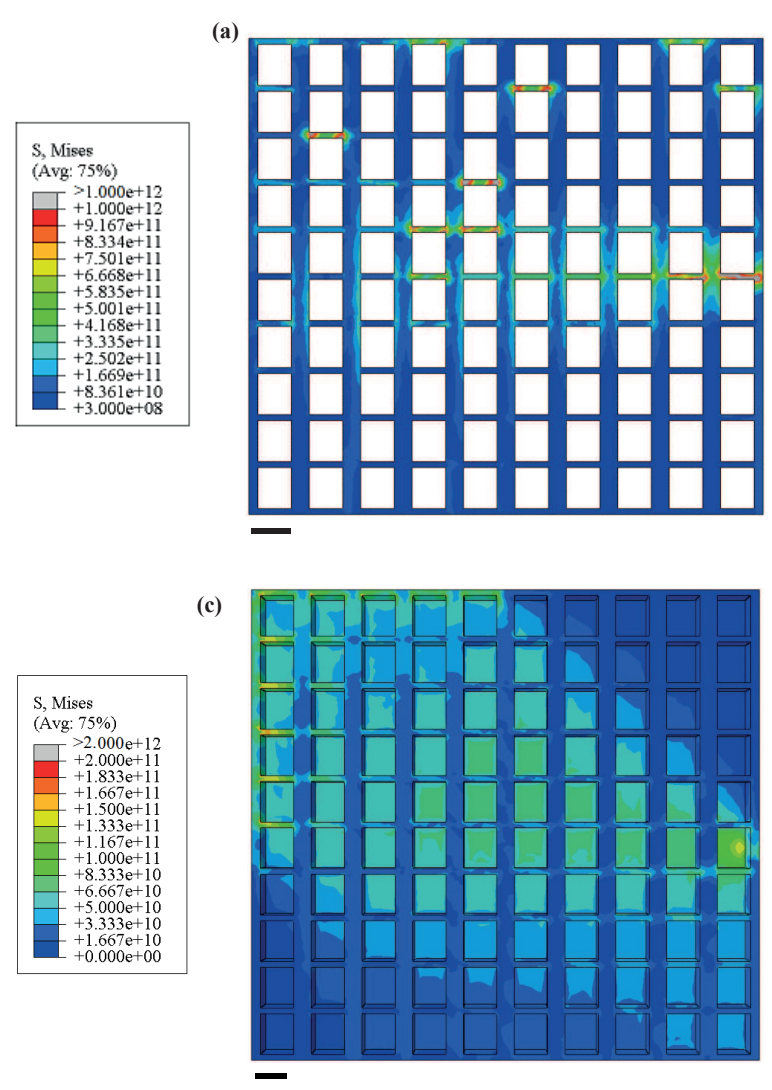

$589 \mu \mathrm{atm}$

(b)

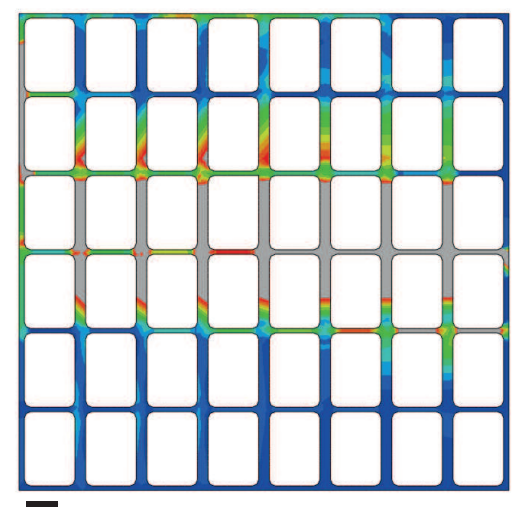

(d)

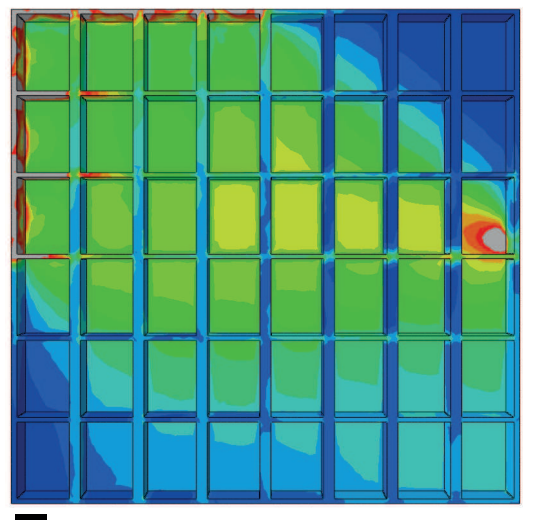

Figure 2. The effect of elevated $\mathrm{CO}_{2}$ on the Lithothamnion glaciale structure. All models are subjected to the same loads and boundary conditions and measurements taken from Ragazzola et al. (2012). Von Mises stresses are projected onto the 2-D Finite element model (a, b) and the 3-D compartmentalised models $(\mathbf{c}, \mathbf{d})$. Warm colours indicate areas of high stress, while cooler blue colours indicate areas of low stress. Units $=\mathrm{Pa}$.

ability of algal communities in maintaining a high level of biodiversity. Finally, the loading and constraint taken from Ragazzola et al. (2012) were a mixture of shear and compressive forces, which simulated boring forces by an organism exerted on the exposed corner of an attached thallus. As it was assumed that these organisms were more prone to shear forces than compressive ones, we also assessed the effect of sole compressive or sole shear forces on the compartmentalised and the biologically realistic model.

\section{Materials and methods}

\subsection{Model geometry}

Four 3-D FE models with different coralline algal features were created based on the measurements and properties of Ragazzola et al. (2012) models. All 3-D geometric models were created and analysed in the Finite Element software package, Abaqus/CAE, v.6.10, (Simula, USA, Dassault Sys- témes, Simula, Providence, RI, USA), following the protocol established by Ragazzola et al. (2012).

Firstly, the 2-D models from Ragazzola et al. (2012) were expanded, using the extrude command in Abaqus, to create a 3-D model with the same area, all length and width dimensions $(78.92 \times 72.46 \mu \mathrm{m})$ were unchanged, but a depth of $80 \mu \mathrm{m}$ was used instead of $1 \mu \mathrm{m}$. Size of the individual cells mirrored that of the $422 \mu \mathrm{atm} \mathrm{CO}_{2}$ model of Ragazzola et al. (2012), with an individual cell height of $6.3 \mu \mathrm{m}$ and width of $5.15 \mu \mathrm{m}$ and an inter- and intra-wall thicknesses of 1.34 and $0.86 \mu \mathrm{m}$ respectively. This structure is assigned the label "Corridor model" (Fig. 3a). The inter-wall thickness was the thickness of a single cell wall in the $x$ direction (within filaments). Therefore the internal walls of the model had two inter-cell walls, whereas the external walls (the left outermost and right outermost) only had one inter-cell wall each. The intra-cell thickness was the cell wall thickness between cells in the $y$ direction. As the rhodolith grows as a set of filaments, there was only one cell wall between two cells in the $y$ direction (Fig. 4). 

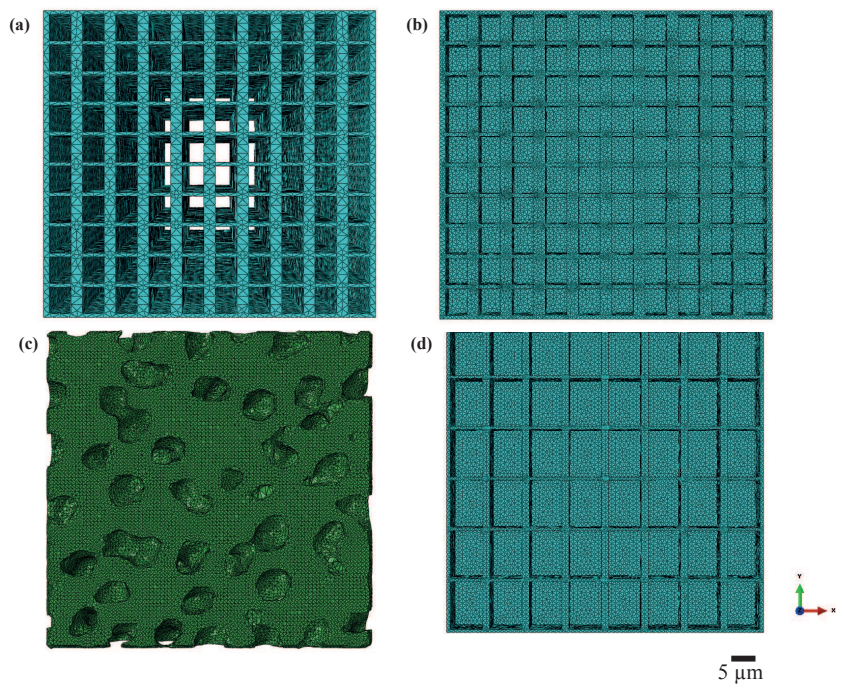

Figure 3. The four computer derived models; (a) The Corridor model, a simple 3-D model; (b) The Compartment model, a compartmentalised model; (c) The Biological model, the biologically realistic model; (d) The OA model, the compartmentalised model under $p \mathrm{CO}_{2}$ conditions simulating the year 2050.

\subsubsection{Compartmentalised (individual cell) model with current/422 $\mu \mathrm{atm} \mathrm{CO}_{2}$ cell size}

Although the cellular width and height in the Corridor model represented the dimensions recorded by Ragazzola et al. (2012) from SEM images, the cells are not represented as discrete entities and instead are represented as hollow calcite "tubes". As algal cells grow apically, they form a lattice of individual cells, hence a second model, "Compartment model" (Fig. 3b) was created in which cell walls were added in the $\mathrm{z}$ direction to create discrete cellular spaces. All dimensions apart from the depth of the individual cells and divisions between cells in the $z$ direction were the same as the corridor model. It was assumed the depth of the cell was the same as the width $(5.15 \mu \mathrm{m})$ and the divisions between the cells in the $z$ direction were the same as the inter-cell wall divisions $(1.34 \mu \mathrm{m})$.

\subsubsection{Biologically realistic model}

Computed tomography (CT) scans of $L$. glaciale derived from the TOMCAT beamline at the Swiss Light source, Switzerland (see Ragazzola et al., 2012) were imported into Avizo V8.0 (VSG) software package. Each scan was 150 projections over $180^{\circ}$ using a $15 \mathrm{keV}$ energy beam with UPLAPO 10x objective. The field of view was $1.5 \times 1.5 \mathrm{~mm}^{2}$ and the pixel size was $0.74 \times 0.74 \mathrm{~mm}^{2}$. A 3-D cube with similar dimensions $(80 \times 80 \times 80 \mu \mathrm{m})$ as the geometric models was created but instead capturing the actual morphology of the rhodolith (known as the "Biological model"; Fig. 3c). The cube was selected at random within the scan of the

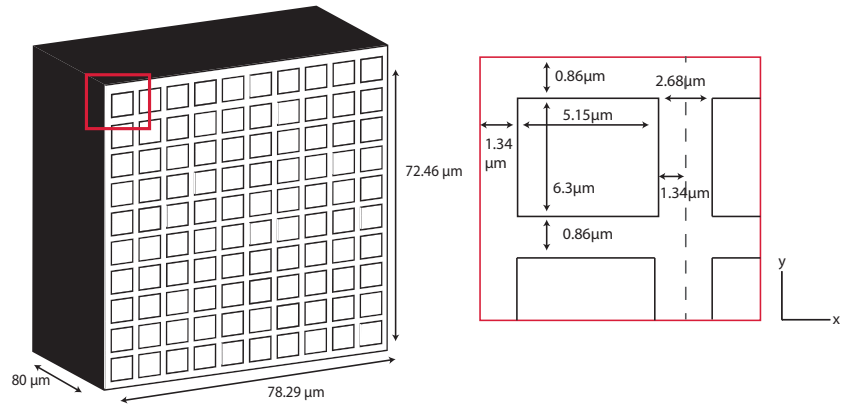

Figure 4. Dimensions used in the 3-D corridor model. Units $=\mu \mathrm{m}$.

rhodolith (Fig. 5a-d), as the summer winter layers could not be distinguished in the CT scan. The scans were thresholded in Avizo and then exported to Hypermesh (v.11; part of the Hyperworks package from Altair, MI, USA) to create FE models, which were analysed in Abaqus v6.10.

\subsubsection{Compartmentalised (individual cell) model with 2050/589 $\mu \mathrm{atm} \mathrm{CO}_{2}$ cellular size}

A final model, "the OA model" (Fig. 3d), was created by adjusting the cell size and spacing to represent the dimensions of the future $589 \mu \mathrm{atm} \mathrm{CO}_{2}$ model as a 3$\mathrm{D}$ and compartmentalised structure with overall dimensions $(74.99 \times 77.2 \times 80 \mu \mathrm{m})$, individual cell dimensions $(11.7 \times 7.99 \times 7.99 \mu \mathrm{m})$ and intra- and inter-cell wall dimensions $(0.685$ and $0.829 \mu \mathrm{m}$ respectively). This future predicted $\mathrm{CO}_{2}$ model was compared to the performance of the 3-D compartment model with current $\mathrm{CO}_{2}$ ppm cell size.

\subsection{Finite element analysis (FEA)}

\subsubsection{Boundary conditions}

In keeping with Ragazzola et al. (2012), a load pressure of $20000 \mathrm{~Pa}$ was applied to the top left corner, $40 \mu \mathrm{m}$ along the external top surface and $40 \mu \mathrm{m}$ down the left surface of the models. Constraints were applied to the whole bottom surface and on the right hand surface, opposite the loads, $40 \mu \mathrm{m}$ up from the constrained bottom (Fig. 6). This simulated the attachment of the structure to the rest of the thallus. Even though the same loads as Ragazzola et al. (2012) were used, it is known that the primary hydrodynamic force exerted on marine macroalgae is drag force (Carrington, 1990). Drag $\left(F_{\text {drag }}\right)$ force can be calculated using Eq. (2).

$F_{\text {drag }}=\frac{1}{2}\left(\rho U^{2} A C_{\mathrm{d}}\right)$,

where $\rho$ is the seawater density (approximately $1025 \mathrm{~kg} \mathrm{~m}^{-3}$ ) and $U$ is the free flow water velocity. Subtidal marine macroalgae experience a water velocity on the order of magnitude of $1 \mathrm{~m} \mathrm{~s}^{-1}$ (Carrington, 1990), while intertidal species can experience breaking waves of 

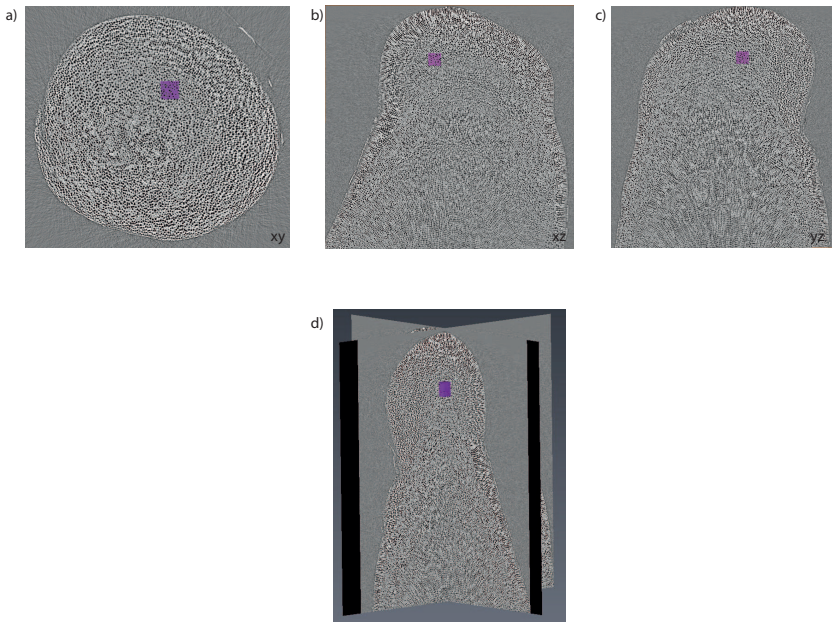

Figure 5. Orthoslice projections in the different planes of a rhodolith thallus: (a) $x y$ direction; (b) $x z$ direction; (c) $y z$ direction and (d) in 3-D format. The purple box highlights where the $80 \mu \mathrm{m} \times 80 \mu \mathrm{m}$ cube was selected.

up to $25 \mathrm{~m} \mathrm{~s}^{-1}$ (Denny et al., 2003). $A$ is the algal planform area; and $C_{\mathrm{d}}$ the drag coefficient (dimensionless index of shape change and reconfiguration of flexible fronds; Carrington, 1990; Dudgeon and Johnson, 1992; Gaylord et al., 1994). However, there are no data published for resulting in breakage of rhodoliths, instead the existing literature focused on flexible macroalgae, making it difficult to find loads that are environmentally significant whilst also being species related.

\subsubsection{Element type and size}

Convergence tests were performed for each mesh type in order to determine the minimum mesh size required. The mesh size was decreased until the average von Mises value no longer changed relative to mesh size. Hypothetically, all refined meshes should converge to similar results yet our converged von Mises stress value was an order of magnitude different between the hexagonal and tetrahedral mesh. This was due to the shape of the tetrahedral elements and the way tetrahedral elements interlock together, making a tetrahedral model stiffer than a hexagonal model. Whereas Dumont et al. (2005) found that comparing a converged 4-node linear and a stiffer 10-node quadrilateral tetrahedral mesh of the same model gave different mean stress values, but within $10 \%$. This shows that even when comparing different forms of the same tetrahedral element, variation in stress is still apparent. Hence when comparing different element types (hexagonal and tetrahedral), we find an even greater difference in variation. Therefore in order to compare the 2$\mathrm{D}$ to 3-D geometric models, the corridor model was meshed with 4-node linear hexagonal elements. As tetrahedral elements were better at capturing the complex geometry of the

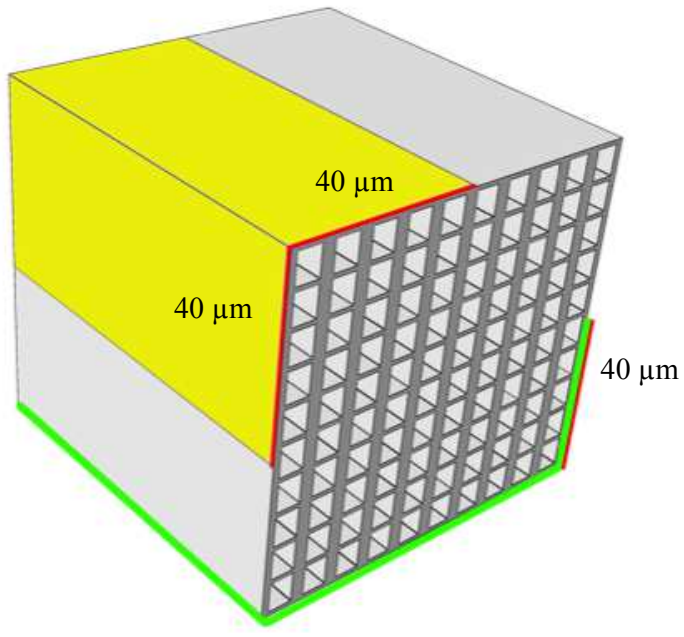

Figure 6. Loads and Boundary constraints. All models had the same loads and constraints applied. Loads, representing wave erosion, were applied to the top left hand corner along a strip $40 \mu \mathrm{m}$ wide at the external top left side of the model (yellow surface). Constraints were applied to the bottom right corner (opposite corner to load) along a strip $40 \mu \mathrm{m}$ wide up the right hand side of the model and over the whole of the bottom model (green lines).

biological model and to account for variation in results depending on element type, all models were then meshed with 4-node linear tetrahedral elements in order to be compared to the biologically realistic model and to each other.

\subsubsection{Material properties}

In keeping with Ragazzola et al. (2012), all models were assumed to be composed of a linearly elastic, isotropic, homogeneous material with a Young's Modulus of $36 \mathrm{GPa}$ and a Poisson ratio of 0.31 (properties of calcite; Tanur et al., 2010). Even though these material properties do not accurately represent the heterogeneities in the specimen and their material properties this approach gives a comparative insight into how different geometries affect the overall strength of a structure.

Initially, to analyse how sensitive the models were to changing material properties, a set of 2-D and 3-D corridor models with different Young's modulus (maximum and minimum Young's modulus values of two different bivalves Mytilus edulis and M. californianus) were analysed.

\subsubsection{Displaying and recording results}

In order to compare the impact of predators on the different 3-D geometric models, stress and strain results were calculated. Stress, generated by the applied load (force) on a given area, is represented by the von Mises stress, a function of each of the principle stresses that represents tensile or compressive stress (Rayfield, 2007). Average stresses were calculated by dividing the von Mises stress by the element size 
Table 1. Mesh type, number of elements, average von Mises stress, 95th percentile of von Mises stress and total strain energy for the different models.

\begin{tabular}{|c|c|c|c|c|c|}
\hline Model & Mesh type & $\begin{array}{r}\text { Number of } \\
\text { elements }\end{array}$ & $\begin{array}{r}\text { Average von Mises } \\
\text { Stress }(\mathrm{Pa})\end{array}$ & $\begin{array}{r}95 \text { percentile of } \\
\text { von Mises Stress }(\mathrm{Pa})\end{array}$ & $\begin{array}{r}\text { Total Strain } \\
\text { Energy }(J)\end{array}$ \\
\hline $422 \mu$ atm 2-D model & Quad & 16368 & $1.67 \mathrm{E}+11$ & & $8.91 \mathrm{E}+08$ \\
\hline $589 \mu$ atm 2-D model & Quad & 1889 & $5.17 \mathrm{E}+11$ & & $1.27 \mathrm{E}+10$ \\
\hline $3-\mathrm{D}$ & hexagonal & 202304 & $1.72 \mathrm{E}+11$ & & $1.11 \mathrm{E}+11$ \\
\hline $3-D^{*}$ & hexagonal & 202304 & & & $4.70 \mathrm{E}+11$ \\
\hline 3-D (Corridor model) & tetrahedral & 2125549 & $7.46 \mathrm{E}+10$ & $2.21 \mathrm{E}+11$ & $1.75 \mathrm{E}+10$ \\
\hline $\begin{array}{l}422 \mu \text { atm compartmentalised } \\
\text { (Compartment model) }\end{array}$ & tetrahedral & 3442433 & $2.75 \mathrm{E}+10$ & $5.36 \mathrm{E}+10$ & $4.28 \mathrm{E}+09$ \\
\hline $\begin{array}{l}589 \mu \text { atm compartmentalised } \\
\text { (OA model) }\end{array}$ & tetrahedral & 1707673 & $4.98 \mathrm{E}+10$ & & $8.81 \mathrm{E}+09$ \\
\hline $\begin{array}{l}\text { Biologically realistic model } \\
\text { (Biological model) }\end{array}$ & tetrahedral & 2106858 & $2.74 \mathrm{E}+10$ & $5.63 \mathrm{E}+10$ & $5.21 \mathrm{E}+09$ \\
\hline
\end{tabular}

* Strain energy corrected for calcite volume.

to account for differing number of elements between models. Total strain energy refers to the energy stored in a system as a load is applied, which is a useful variable to record in mineralised structures as the more strain in a system leads to a larger amount of potential energy available for fracture (Gordon, 1978). The 95th percentile of von Mises stress was additionally used as a comparison between the corridor, compartment and biological models as this metric highlighted the extremes of the von Mises Stress distribution - an important parameter to highlight fracture potential.

Stress and strain energy are linearly dependent on surface area and volume respectively (Dumont et al., 2009), hence the applied pressure was rescaled for the biological model to rule out the effect of increased Mg-calcite volume on modelling stress and strain. To account for the increase in volume of calcite between the 2-D and the 3-D model, as strain energy is dependent on volume, the strain energy was calculated for the 3-D model using Eq. (3), outlined by Dumont et al. (2009);

$U_{\mathrm{B} *}=\left(V_{\mathrm{B}} / V_{\mathrm{A}}\right)^{1 / 3}\left(F_{\mathrm{A}} / F_{\mathrm{B}}\right)^{2} U_{\mathrm{B}}$,

where $U_{\mathrm{B} *}$ is the total strain energy for model B corrected for calcite volume, $V_{\mathrm{A}}$ and $V_{\mathrm{B}}$ are the volumes for the models A and $\mathrm{B}$ respectively, $F_{\mathrm{A}}$ and $F_{\mathrm{B}}$ are the loads applied to the two models and $U_{\mathrm{B}}$ is the total strain energy for model B.

The von Mises stress was displayed graphically on the model, with warm colours (red/orange) indicating areas of high stress and cool colours (blue) indicating areas of low stress. Stress distribution throughout the model was very similar to surface stress distribution. The surfaces of the model were more sensitive to the loads and constraints, due to immediate contact with the boundary conditions. The minimum and maximum von Mises stress values were found on the surfaces of the models, being more influenced by the position of the boundary conditions and complexities in the geometry. Hence, the minimum and maximum values did not provide any additional information on the overall structural integrity of the model than that provided by the surface contour plots. Average von Mises stress values, total strain energies and 95th percentile of von Mises stress can be found in Table 1.

\subsection{Comparison between shear and compressive loading}

The biological and the compartment model were exposed to different loading scenarios in Abaqus. This included the original load setup explained earlier in Sect. 2.1.4 (Fig. 7a); the compressive loads, where the load was applied to the top of the cube opposite the constraint (Fig. 7b); and shear loads, where the load was applied on the face adjacent to the bottom constraint (Fig. 7c).

As this part of the study moved on from the initial research of Ragazzola et al. (2012), it was decided to use loads defined experimentally based on real-wave velocities. Starko et al. (2015) used wave velocities of up to $3.5 \mathrm{~m} \mathrm{~s}^{-1}$ to assess the effect of branching in flexible wave-swept macroalgae, in which they also measured the drag force. Water velocity experienced by subtidal marine macroalgae is on the order of magnitude of $1 \mathrm{~m} \mathrm{~s}^{-1}$ (Carrington, 1990). Hence, we used a drag force $(0.9 \mathrm{~N})$ measured for a heavily branched macroalgae (similar in branching to our rhodoliths) with an algal planform area of $48.20 \mathrm{~cm}^{2}$ that experienced a wave velocity of $3.5 \mathrm{~m} \mathrm{~s}^{-1}$ to carry out our load type comparison tests (Starko et al., 2015). Here we have kept the force per unit area constant in order to compare the compartment model to the biological model. Strain energy is dependent on volume, therefore in order to compare the total strain energy between the models we had to take into account the difference in calcite volume between the biological model and the compartment model (using Eq. (3); Dumont et al., 2009). 


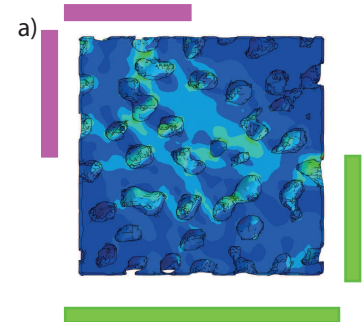

d)

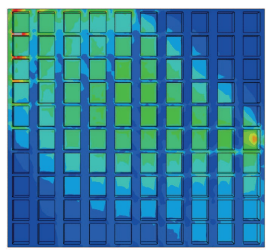

b)

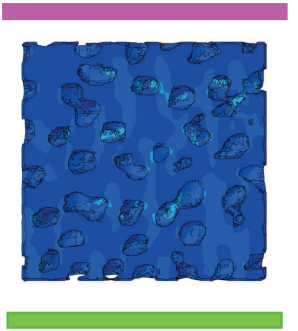

e)

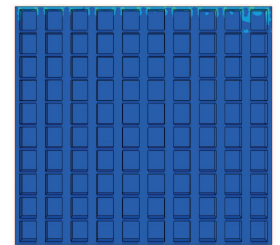

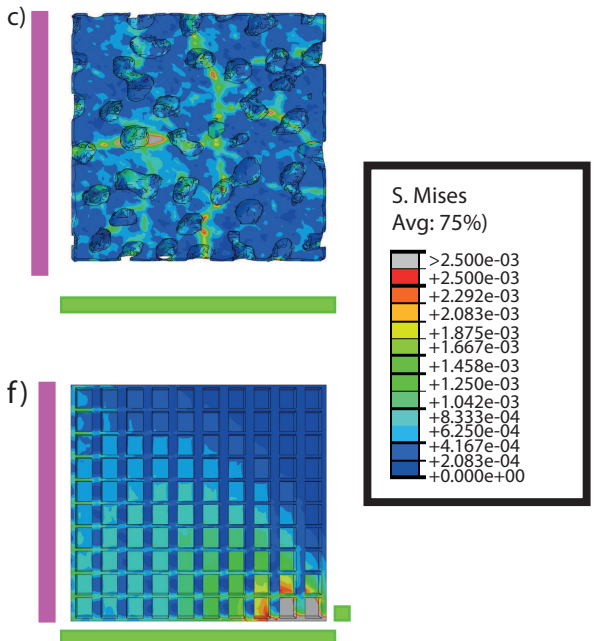

Figure 7. The von Mises stress patterns on the biological model $(\mathbf{a}, \mathbf{b}, \mathbf{c})$ and the compartment model (d, e, f) in different loading situations; the original (mixture of both shear and compressive loads, a, d); compressive load (b, e) and the shear load (c, f). The different load situations (pink box) are shown on the biological model as well as the constraints (green boxes). The shear load for the compartment model was set up

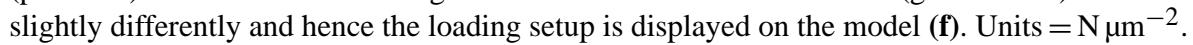

\section{Results}

A similar stress distribution was observed in the 2-D and 3-D geometric model (Corridor model; Fig. 8a-b), with areas of high stress occurring along the intra-cell walls and adjacent to the constrained surface. The average von Mises stress of the two models was very similar (Table 1), indicating that the simple 2-D model (Fig. 8a) was an accurate representation of the stress in a simple 3-D geometric model (Fig. 8b). As expected, the total strain energy in the 3-D model was over $500 \times$ higher than the 2-D model, showing that the 3-D model with a larger volume was able to store more than the relative amount of strain energy compared to the 2-D model.

Once the complexity of the 3-D model was increased to better represent the natural structural complexity, differences between the simple 3-D model (Corridor model) and the more complex models became evident (Fig. 9a-c). In the compartment model of current $\mathrm{CO}_{2}$ conditions (Fig. 9b), both the average stress and total strain energies were lower than the Corridor model (63 and $76 \%$ respectively; Table 1). The addition of cellular walls in the $\mathrm{z}$ direction removed regions of peak stress near the constraints as stresses now dissipated throughout the structure, stabilising the model.

The results of the comparison between the 3-D geometric models (the Corridor and Compartment model) and the realistic model of similar dimensions generated from CT scans (the Biological model) showed that a similar average stress, strain energy (Table 1) and stress distribution (Fig. 9b-c) was observed between the compartment model and the biological model. Comparison of the internal morphology between the compartment model and the biological model also showed similarities. Both models had regularly distributed
Table 2. Percentage volumes of calcite and cavities in the biological model, the corridor and the compartment model.

\begin{tabular}{lrrr}
\hline & $\begin{array}{r}\text { Biological } \\
\text { Model }\end{array}$ & $\begin{array}{r}\text { 3-D Corridor } \\
\text { model }\end{array}$ & $\begin{array}{r}\text { 3-D Compartment } \\
\text { model }\end{array}$ \\
\hline $\begin{array}{l}\text { volume of calcite } \\
\left(\mu \mathrm{m}^{3}\right)\end{array}$ & $3.09 \mathrm{E}+05$ & $1.94 \mathrm{E}+05$ & $2.87 \mathrm{E}+05$ \\
$\begin{array}{l}\text { volume of cavities } \\
\left(\mu \mathrm{m}^{3}\right)\end{array}$ & $1.83 \mathrm{E}+05$ & $2.60 \mathrm{E}+05$ & $1.67 \mathrm{E}+05$ \\
$\begin{array}{l}\text { percentage of calcite } \\
\text { percentage of cavities }\end{array}$ & $63 \%$ & $43 \%$ & $63 \%$ \\
\hline
\end{tabular}

cavities. However unlike the compartment model the biological model cavities were spheroidal and, due to the natural variation within these specimens, the arrangement of cavities was not as regimented as in the compartment model (Fig. 10). Both the biological model and the compartment model had the same percentage volumes of calcite and cavities whereas the corridor model had a lower percentage volume of calcite (Table 2).

As the compartment model was similar in performance to the biological model, we used this model to assess the impact of ocean acidification (Fig. 2c-d). The change in wall thickness and cell size in the $589 \mu \mathrm{atm} / 2050$ model led to a near doubling of average stress and a doubling of the total strain energy (Table 1). This increase in strain energy was less than suggested using the simple 2-D models, which predicted an increase in average stress of $309 \%$ and strain energy of $1421 \%$.

However, using more environmentally significant forces in the shear and compressive comparison tests, we can see that the stresses and strains exerted by these organisms were 


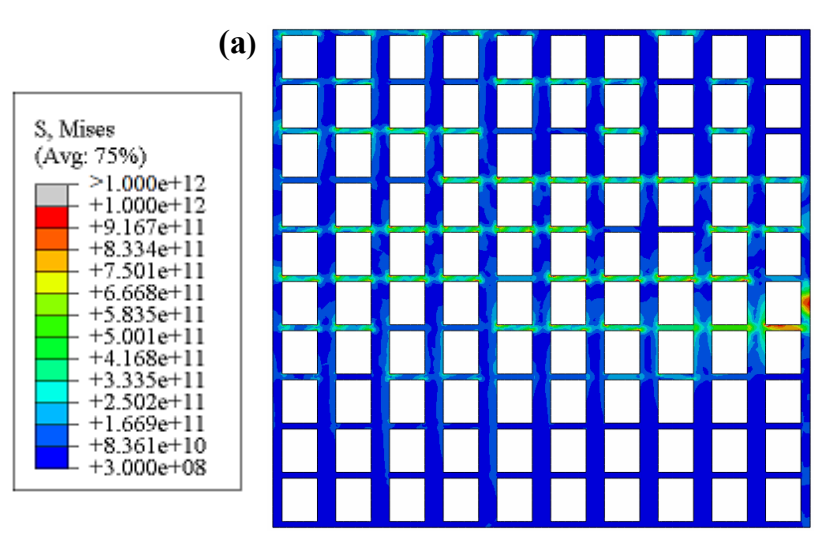

(b)

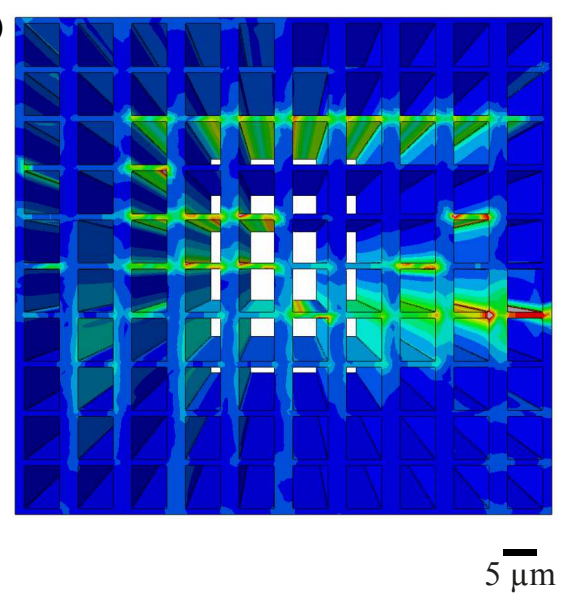

higher stress was restricted to the top of the model where the load was applied (Fig. 7e) and under the shear load setup, the area of high stress spread from the right hand side near the constrained corner (Fig. 7f). The average von Mises stress, 95th percentile of von Mises stress and the total strain energy were largest under sole shear loads and smallest in the compressive load model, with values for the original set up falling in between (Table 3).

Note the shear load in the compartment model was applied differently to the arrangement for the biological model. As the compartment model was not able to run under a sole shear load, like the biological model, a small constraint on the opposite face $(1 \mu \mathrm{m})$ was added to help stabilise the model (Fig. 7f). The compartment model did not run under the sole shear load as it experienced extremely high stresses at the interface between the bottom constraint and the adjacent unconstrained surface.

The sensitivity test of the 2-D model and the 3-D corridor model highlighted that increasing the Young's modulus by $120 \%$ did not result in any change in stress, whereas the total strain energy decreased with increasing Young's modulus (Table 4).

\section{Discussion}

Ragazzola et al. (2012) used 2-D FE models to predict if changes to coralline algae cellular morphology induced by higher $\mathrm{CO}_{2}$ concentrations generate a structure that might be less well able to withstand stresses compared to current specimens. They predicted that increased $\mathrm{CO}_{2}$ and resulting ocean acidification will create a structure more susceptible to fracture in response to environmental stressors such as wave action and boring. This 2-D model was the first step in assessing the structural and mechanical consequences of high $\mathrm{CO}_{2}$-induced changes to growth structure, but it is important to note that it represented a 2-D approximation of a complex 3-D structure. Here our results showed that a 3-D extrapolation of the 2-D FE model (Corridor model) generated comparable patterns and magnitudes of average stress to the 2-D model. However, once the complexity of the 3-D model was altered to approximate cellular compartments and compared to a biologically realistic model generated from computed tomography (CT) data, it became clear that stress and strain energy magnitudes in the simple 2-D and 3-D models were an over-estimation.

Coralline algae grow apically with lateral cell fusion being very common (Irvine and Chamberlain, 1994). This creates a vast network of individual cells able to oppose stress in all directions (Gordon, 1978). The importance of these structures is highlighted by the geometric model with compartments (the Compartment model) being the most stable of the geometric structures assessed and also most comparable in terms of percentage volume of calcite, stress distribution and magnitudes of average stress and total strain energy - 


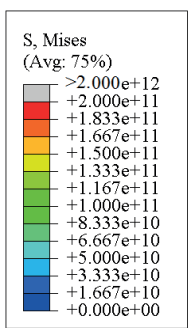

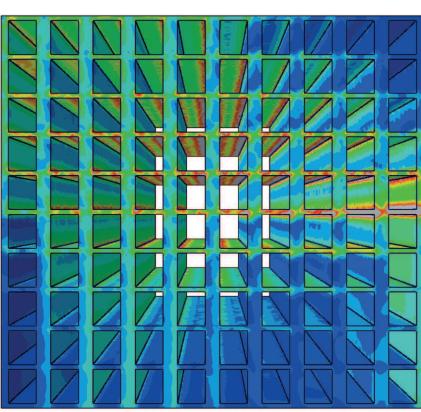

(b)

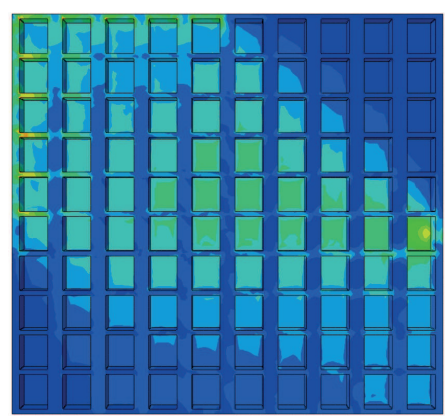

(c)

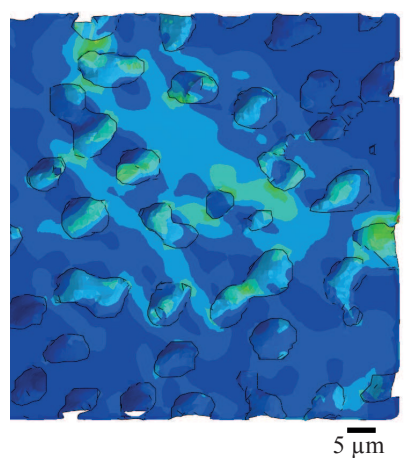

Figure 9. Comparison of all 3-D models. (a) The 3-D corridor model (b) the compartment model and (c) the biological model. Units $=$ Pa.

Table 3. Average von Mises stress, 95th percentile of von Mises stress and total strain energy for the different load types exerted on the biological, compartment and corridor models. Total strain energy for the biological model has been corrected for calcite volume (Eq. 2). The compartment model under the shear loading type is highlighted in bold to reiterate that the loading setup is different to the biological model under a shear loading type.

\begin{tabular}{|c|c|c|c|c|}
\hline Model & Loading type & $\begin{array}{r}\text { Average von Mises Stress } \\
\left(\mathrm{N} \mu \mathrm{m}^{-2}\right)\end{array}$ & 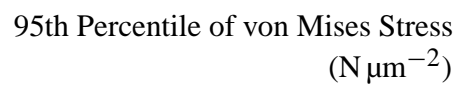 & $\begin{array}{r}\text { Total Strain } \\
\text { Energy }(\mathrm{J})\end{array}$ \\
\hline \multirow[t]{3}{*}{ Biological } & Compressive & 2.34E-04 & $4.08 \mathrm{E}-04$ & $3.34 \mathrm{E}+05$ \\
\hline & Shear & $2.83 \mathrm{E}-04$ & 6.07E-04 & $6.11 \mathrm{E}+05$ \\
\hline & Original (Shear + Compressive) & $3.49 \mathrm{E}-04$ & 7.21E-04 & $9.73 \mathrm{E}+05$ \\
\hline \multirow[t]{3}{*}{ Compartment } & Compressive & 2.42E-04 & 2.96E-04 & $2.34 \mathrm{E}+05$ \\
\hline & Shear & 4.27E-04 & 1.03E-03 & $1.63 E+06$ \\
\hline & Original (Shear + compressive) & $4.10 \mathrm{E}-04$ & $8.25 \mathrm{E}-04$ & $9.63 \mathrm{E}+05$ \\
\hline
\end{tabular}

to the biological model (Tables 1 and 2). This highlights the importance of geometry changes, which our method accurately captured, to the distribution and magnitude of stress. This occurrence was also observed by Romeed et al. (2006) who previously found that changes in the geometry between their 2-D and 3-D models of a restored premolar tooth also affected their displacement and profile stresses.

Creating the FE model of the biologically realistic structure (the Biological model) from CT data was a time consuming process compared to the user effort required to generate the compartmentalised geometric model (the Compartment model). As these different models produced very similar measures of average stress $(2.75 \mathrm{E}+10 \mathrm{~Pa}$ compared to $2.74 \mathrm{E}+10 \mathrm{~Pa}$ for the geometric and the biological model respectively), comparable measures of total strain energy
$(4.28 \mathrm{E}+09 \mathrm{~J}$ compared to $5.21 \mathrm{E}+09 \mathrm{~J})$ and a similar stress distribution, we propose that the compartment model presented a time-efficient opportunity to manipulate geometric features to test hypotheses of mechanical performance and structural integrity.

Hence this model was used to assess the impact of ocean acidification changes to the cell growth on structural integrity. When the cellular size of the 3-D model was adjusted to reflect $589 \mu \mathrm{atm}$ growth conditions, the structure was less "efficient" than the structure under current environmental conditions, with a higher average stress and total strain energy. It is important to note that the increase in stress and total strain energy magnitude was less pronounced than that suggested by the 2-D models, indicating that the extra cellular walls aided in stabilising the thinner cell walls of the model. 
Table 4. Average von Mises stress and total strain energy for the comparison of the different material properties in the 2-D and 3-D corridor models.

\begin{tabular}{lrrr}
\hline Pa) & $\begin{array}{r}\text { Young's Modulus } \\
\text { Stress (Pa) }\end{array}$ & $\begin{array}{r}\text { Average von Mises } \\
\text { Energy (J) }\end{array}$ & Total Strain \\
\hline 2-D & & & \\
Calcite & $3.60 \mathrm{E}+10$ & $1.67 \mathrm{E}+11$ & $8.91 \mathrm{E}+08$ \\
M.edulis -Min & $4.39 \mathrm{E}+10$ & $1.67 \mathrm{E}+11$ & $7.30 \mathrm{E}+08$ \\
M.californianus -Min & $4.79 \mathrm{E}+10$ & $1.67 \mathrm{E}+11$ & $6.69 \mathrm{E}+08$ \\
M.edulis -Max & $7.18 \mathrm{E}+10$ & $1.67 \mathrm{E}+11$ & $4.47 \mathrm{E}+08$ \\
M.californianus -Max & $7.93 \mathrm{E}+10$ & $1.67 \mathrm{E}+11$ & $4.04 \mathrm{E}+08$ \\
\hline & Young's Modulus & Average von Mises & Total Strain \\
& $(\mathrm{Pa})$ & Stress $(\mathrm{Pa})$ & energy (J) \\
\hline 3-D corridor & & & \\
Calcite & $3.60 \mathrm{E}+10$ & $7.46 \mathrm{E}+10$ & $1.75 \mathrm{E}+10$ \\
M.edulis -Min & $4.39 \mathrm{E}+10$ & $7.46 \mathrm{E}+10$ & $1.43 \mathrm{E}+10$ \\
M.californianus -Min & $4.79 \mathrm{E}+10$ & $7.46 \mathrm{E}+10$ & $1.31 \mathrm{E}+09$ \\
M.edulis -Max & $7.18 \mathrm{E}+10$ & $7.46 \mathrm{E}+10$ & $8.77 \mathrm{E}+09$ \\
M.californianus -Max & $7.93 \mathrm{E}+10$ & $7.46 \mathrm{E}+10$ & $7.94 \mathrm{E}+08$ \\
\hline
\end{tabular}

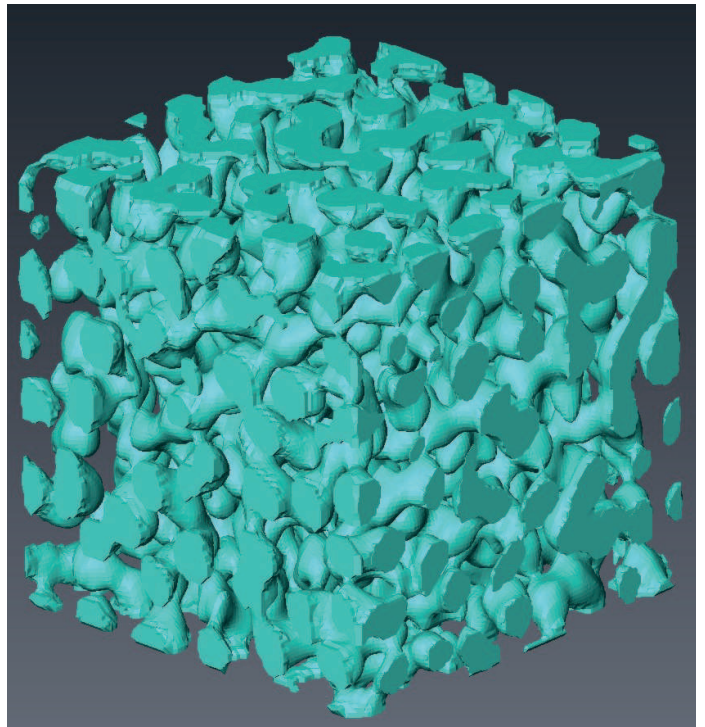

Figure 10. The inside spheroidal cavities of the biological model.

This finding was in agreement with other work showing that microstructural features affect the mechanical properties of cellular solids (Gibson, 2005). For example, wood has a stiffness to weight ratio equal to steel, which is partly due to the arrangement of cells in a honeycomb structure (Gibson et al., 2010). Hence these features provide habitat forming organisms with a larger structural integrity to withstand external pressures and the ability to live in a highly dynamic environment such as the coastal shelf.

Although our geometric and biological models show congruence, they are still simplifications of the heterogeneities in the algal skeleton. A factor which was not considered in this study is the potential effect of changing material properties due to global change on the algal skeleton. Material properties are affected by the concentration of $\mathrm{Mg}$ in the skeleton (Ma et al., 2008), which is dependent on temperature (Kamenos et al., 2008) and potentially pH (Ragazzola et al., 2013; Ries, 2011). Mg incorporated into the calcite lattice increases the lattice distortion, which causes an increase in the sliding resistance and deformation resistance to crystals (Wang et al., 1997). Ma et al. (2008) found that due to a much larger difference in $\mathrm{mol} \%$ of $\mathrm{MgCO}_{3}$ (just below $40 \%$ ), the high $\mathrm{Mg}$-calcite polycrystalline matrix of the tooth of a sea urchin had a significantly higher elastic modulus $(E)$ and hardness $(H)$ value than both synthetic calcite and the single crystalline needles.

Sea surface temperatures in the North Atlantic are predicted to rise $2.5^{\circ} \mathrm{C}$ by the end of the century (Rhein et al., 2013). This rise in temperature corresponds to a $3 \%$ increase in mol \% of $\mathrm{MgCO}_{3}$ (Kamenos et al., 2008). As a $3 \%$ change in $\mathrm{mol} \%$ of $\mathrm{MgCO}_{3}$ is within the natural variation between specimens (Ragazzola et al., 2013), we suggest such a mol \% change in $\mathrm{MgCO}_{3}$ will not significantly impact the material properties and hence affect the skeleton. However Ma et al. (2008) also suggested the large difference in material properties was not due to just the difference in mol \% of $\mathrm{MgCO}_{3}$ but also due to the orientation and uniform size of the crystals. This illustrates that $\mathrm{Mg} / \mathrm{Ca}$ ratios are not the only factor which affects material properties.

Proteins are also known to affect material properties as the incorporation of organic macromolecules reduces the brittleness and enables plastic deformation (Berman et al., 1988; Ma et al., 2008; Wang et al., 1997; Weiner et al., 2000). The presence of chitin and collagen within the skeleton of Clathromorphum compactum aids calcification and increases 
skeletal strength (Rahman and Halfar, 2014). Implementing accurate material properties specific for specimens grown under a wide range of conditions into the model would allow a more accurate assessment of whether phenotypic variability in material properties has the potential to counteract structural changes in response to ocean acidification.

However, using these more biologically accurate models, we have further supported previous results that state future climate change will lead to a loss in the structural integrity of coralline algae. We have shown that by increasing the complexity of a simple 2-D geometric model to a 3-D geometric model we can obtain informative data on the effect of ocean acidification on the structural integrity of the coralline algal skeleton, without the need for complex real biological models derived from CT scanning that take ample computer time to construct and analyse. As responses to climate change are species-specific, we are therefore able to create models tailor made to individual species and analyse how they react to future climate change. We have also shown the susceptibility these models have to shear loads rather than compressive loads.

As the oceans are becoming more acidic, with concurrent calcification pressure, it is vital to understand the potential effect of ocean acidification on the skeletons of these habitatforming organisms to infer whether they are able to maintain habitats in the future. As coralline algae are major habitat formers, with the diversity and abundance of species dependent on their structural complexity, weakening of the skeleton under high $\mathrm{CO}_{2}$ conditions will affect the organisms that rely on coralline algae as a habitat with important consequences for marine ecosystems. Our model results, along with bioerosion, rising sea levels (Rhein et al., 2013) and predicted increases in frequency and intensity of storm surges (Knutson et al., 2010) strongly suggest that coralline algae will be under more intense environmental pressure in future $\mathrm{CO}_{2}$ scenarios.

It is important to note that recent long-term studies have shown calcifying organisms acclimating to ocean acidification for example cold-water corals sustaining growth rates (Form and Riebesell, 2012) or coralline algae decreasing growth rates to maintain cell wall thickness (Ragazzola et al., 2013). The consequence of this sustained growth on the material properties and structural integrity has not been assessed and poses an open question with regards to their ability to provide habitats in the future.

Author contributions. Leanne Melbourne and Julia Griffin carried out the experiments under the guidance of Daniela Schmidt and Emily Rayfield. Leanne Melbourne prepared the manuscript with contributions from all co-authors.

Acknowledgements. The authors would like to thank NERC studentship award [NE/L501554/1] and the Natural History Museum,
London for LAM and a Royal Society URF for DNS for providing funding, Federica Ragazzola for allowing access to FE models and Jen Bright and Phil Anderson for general help with modelling aspects. The tomographic scans from Ragazzola et al. (2012) were taken on the TOMCAT beamline at the Swiss Light Source, Paul Scherrer Institut, Villigen, Switzerland. European Commission under the 7th Framework Programme: Research Infrastructures. We also would like to thank our reviewers, C. Evenhuis and an anonymous reviewer, whose valuable comments provided improvements to our paper.

Edited by: J. Middelburg

\section{References}

Amado-Filho, G. M., Moura, R. L., Bastos, A. C., Salgado, L. T., Sumida, P. Y., Guth, A. Z., Francini-Filho, R. B., Pereira-Filho, G. H., Abrantes, D. P., Brasileiro, P. S., Bahia, R. G., Leal, R. N., Kaufman, L., Kleypas, J. A., Farina, M., and Thompson, F. L.: Rhodolith Beds Are Major $\mathrm{CaCO}_{3}$ Bio-Factories in the Tropical South West Atlantic, PLoS ONE, 7, e35171, doi:10.1371/Journal.pone.0035171, 2012.

Andersen, L. and Jones, C.: Coupled boundary and finite element analysis of vibration from railway tunnels - a comparison of two-and three-dimensional models, J. Sound Vib., 293, 611-625, 2006.

Andersson, A. J., Mackenzie, F. T., and Bates, N. R.: Life on the margin: implications of ocean acidification on Mg-calcite, high latitude and cold-water marine calcifiers, Mar. Ecol.-Prog. Ser., 373, 265-273, 2008.

Berman, A., Addadi, L., and Weiner, S.: Interactions of sea-urchin skeleton macromolecules with growing calcite crystals - a study of intracrystalline proteins, Nature, 331, 546-548, 1988.

Brodie, J., Williamson, C. J., Smale, D. A., Kamenos, N. A., Mieszkowska, N., Santos, R., Cunliffe, M., Steinke, M., Yesson, C., Anderson, K. M., Asnaghi, V., Brownlee, C., Burdett, H. L., Burrows, M. T., Collins, S., Donohue, P. J. C., Harvey, B., Foggo, A., Noisette, F., Nunes, J., Ragazzola, F., Raven, J. A., Schmidt, D. N., Suggett, D., Teichberg, M., and Hall-Spencer, J. M.: The future of the northeast Atlantic benthic flora in a high $\mathrm{CO}_{2}$ world, Ecol. Evol., 4, 2787-2798, 2014.

Caldeira, K. and Wickett, M. E.: Oceanography: anthropogenic carbon and ocean pH, Nature, 425, 365-365, 2003.

Carrington, E.: Drag and dislodgment of an intertidal macroalga: consequences of morphological variation in Mastocarpus papillatus Kützing, J. Exp. Mar. Biol. Ecol., 139, 185-200, 1990.

Ciais, P., Sabine, C., Bala, G., Bopp, L., Brovkin, V., Canadell, J., Chhabra, A., DeFries, R., Galloway, J., Heimann, M., Jones, C., Quéré, C. L., Myneni, R. B., and Thornton, S. P. A. P.: Carbon and Other Biogeochemical Cycles, in: Climate Change 2013: The Physical Science Basis. Contribution of Working Group I to the Fifth Assessment Report of the Intergovernmental Panel on Climate Change, edited by: Stocker, T. F., Qin, D., Plattner, G. K., Tignor, M., Allen, S. K., Boschung, J., Nauels, A., Xia, Y., Bex, V., and Midgley, P. M., Cambridge University Press, Cambridge, United Kingdom and New York, NY, USA, 465$570,2013$. 
Denny, M. W., Miller, L. P., Stokes, M. D., Hunt, L. J. H., and Helmuth, B. S. T.: Extreme Water Velocities: Topographical Amplification of Wave-Induced Flow in the Surf Zone of Rocky Shores, Limnol. Oceanogr., 48, 1-8, 2003.

Diaz-Pulido, G., Gouezo, M., Tilbrook, B., Dove, S., and Anthony, K. R. N.: High $\mathrm{CO}_{2}$ enhances the competitive strength of seaweeds over corals, Ecol. Lett., 14, 156-1-62, 2011.

Dudgeon, S. R. and Johnson, A. S.: Thick vs. thin: thallus morphology and tissue mechanics influence differential drag and dislodgement of two co-dominant seaweeds, J. Exp. Mar. Biol. Ecol., 165, 23-43, 1992.

Dumont, E., Grosse, I., and Slater, G.: Requirements for comparing the performance of finite element models of biological structures, J. Theor. Biol., 256, 96-103, 2009.

Dumont, E. R., Piccirillo, J., and Grosse, I. R.: Finite-element analysis of biting behavior and bone stress in the facial skeletons of bats, Anat. Rec. Part A, 283A, 319-330, 2005.

Fabricius, K. E., Langdon, C., Uthicke, S., Humphrey, C., Noonan, S., De'ath, G., Okazaki, R., Muehllehner, N., Glas, M. S., and Lough, J. M.: Losers and winners in coral reefs acclimatized to elevated carbon dioxide concentrations, Nature Climate Change, 1, 165-169, 2011.

Form, A. U. and Riebesell, U.: Acclimation to ocean acidification during long-term $\mathrm{CO}_{2}$ exposure in the cold-water coral Lophelia pertusa, Glob. Change Biol., 18, 843-853, 2012.

Foster, M. S.: Rhodoliths: between rocks and soft places, J. Phycol., 37, 659-667, 2001.

Foster, M. S., Amado Filho, G. M., Kamenos, N. A., RiosmenaRodríguez, R., and Steller, D. L.: Rhodoliths and Rhodolith Beds, Smithsonian Contributions to the Marine Sciences, 39, 143-155, 2013.

Freiwald, A. and Henrich, R.: Reefal coralline algal build-ups within the Arctic Circle: morphology and sedimentary dynamics under extreme environmental seasonality, Sedimentology, 41, 963-984, 1994.

Gaylord, B., Blanchette, C. A., and Denny, M. W.: Mechanical Consequences of Size in Wave-Swept Algae, Ecol. Monogr., 64, 287-313, 1994

Gibson, L. J.: Biomechanics of cellular solids, J. Biomech., 38, 377-399, 2005.

Gibson, L. J., Ashby, M. F., and Harley, B. A.: Cellular materials in nature and medicine, Cambridge University Press, New York, 85-125, 2010.

Gordon, J.: Structures: or Why Things Don't Fall Down, Penguin Books, New York, 35-324, 1978.

Grall, J. and Hall-Spencer, J. M.: Problems facing maerl conservation in Brittany, Aquatic Conservation: Marine and Freshwater Ecosystems, 13, S55-S64, 2003.

Irvine, L. M. and Chamberlain, Y. M.: Volume 1 Rhodophyta Part 2B Corallinales, Hildenbrandiales, Natural History Museum, London, 1-30, 1994.

Kamenos, N., Cusack, M., and Moore, P.: Coralline algae are global palaeothermometers with bi-weekly resolution, Geochim. Cosmochim. Ac., 72, 771-779, 2008.

Kamenos, N. A., Burdett, H. L., Aloisio, E., Findlay, H. S., Martin, S., Longbone, C., Dunn, J., Widdicombe, S., and Calosi, P.: Coralline algal structure is more sensitive to rate, rather than the magnitude, of ocean acidification, Glob. Change Biol., 19, 3621$3628,2013$.
Knutson, T. R., McBride, J. L., Chan, J., Emanuel, K., Holland, G., Landsea, C., Held, I., Kossin, J. P., Srivastava, A., and Sugi, M.: Tropical cyclones and climate change, Nature Geoscience, 3, 157-163, 2010.

Kroeker, K. J., Kordas, R. L., Crim, R. N., and Singh, G. G.: Metaanalysis reveals negative yet variable effects of ocean acidification on marine organisms, Ecolog. Lett., 13, 1419-1434, 2010.

Ma, Y., Cohen, S. R., Addadi, L., and Weiner, S.: Sea Urchin Tooth Design: An "All-Calcite" Polycrystalline Reinforced Fiber Composite for Grinding Rocks, Advanced Materials, 20, 1555-1559, 2008.

Mackenzie, F. T., Lerman, A., and Andersson, A. J.: Past and present of sediment and carbon biogeochemical cycling models, Biogeosciences, 1, 11-32, doi:10.5194/bg-1-11-2004, 2004.

Nelson, W.: Calcified macroalgae-critical to coastal ecosystems and vulnerable to change: a review, Mar. Freshwater Res., 60, 787801, 2009.

Pörtner, H. O., Karl, D., Boyd, P. W., Cheung, W., Lluch-Cota, S. E., Nojiri, Y., Schmidt, D. N., and Zavialov, P.: Ocean systems, in: Climate Change 2014: Impacts, Adaptation, and Vulnerability, Part A: Global and Sectoral Aspects, Contribution of Working Group II to the Fifth Assessment Report of the Intergovernmental Panel of Climate Change, edited by: Field, C. B., Barros, V. R., Dokken, D. J., Mach, K. J., Mastrandrea, M. D., Bilir, T. E., Chatterjee, M., Ebi, K. L., Estrada, Y. O., Genova, R. C., Girma, B., Kissel, E. S., Levy, A. N., MacCracken, S., Mastrandrea, P. R., and White, L. L., Cambridge University Press, Cambridge, United Kingdom and New York, NY, USA, 411-484, 2014.

Ragazzola, F., Foster, L. C., Form, A., Anderson, P. S. L., Hansteen, T. H., and Fietzke, J.: Ocean acidification weakens the structural integrity of coralline algae, Glob. Change Biol., 18, 2804-2812, 2012.

Ragazzola, F., Foster, L. C., Form, A. U., Buscher, J., Hansteen, T. H., and Fietzke, J.: Phenotypic plasticity of coralline algae in a High $\mathrm{CO}_{2}$ world, Ecol. Evol., 3, 3436-3446, 2013.

Rahman, M. A. and Halfar, J.: First evidence of chitin in calcified coralline algae: new insights into the calcification process of Clathromorphum compactum, Sci. Rep., 4, 6162 pp., 2014.

Rayfield, E. J.: Finite element analysis and understanding the biomechanics and evolution of living and fossil organisms, Annu. Rev. Earth Planet. Sci., 35, 541-576, 2007.

Rhein, M., Rintoul, S., Aoki, S., Campos, E., Chambers, D., Feely, R., Gulev, S., Johnson, G., Josey, S., Kostianoy, A., Mauritzen, C., Roemmich, D., and Wang, L. T. a. F.: Observations: Ocean, in: Climate Change 2013: The Physical Science Basis, Contribution of Working Group I to the Fifth Assessment Report of the Intergovernmental Panel on Climate Change Cambridge Univetsity Press, Cambridge, United Kingdom and New York, NY, USA, 1535 pp., 2013.

Ries, J. B.: Skeletal mineralogy in a high- $\mathrm{CO}_{2}$ world, J. Exp. Mar. Biol. Ecol., 403, 54-64, 2011.

Ries, J. B., Cohen, A. L., and McCorkle, D. C.: Marine calcifiers exhibit mixed responses to $\mathrm{CO}_{2}$-induced ocean acidification, $\mathrm{Ge}$ ology, 37, 1131-1134, 2009.

Romeed, S., Fok, S., and Wilson, N.: A comparison of 2-D and 3-D finite element analysis of a restored tooth, J. Oral Rehabil., 33, 209-215, 2006. 
Starko, S., Claman, B. Z., and Martone, P. T.: Biomechanical consequences of branching in flexible wave-swept macroalgae, New Phytol., 206, 133-140, 2015.

Tanur, A., Gunari, N., Sullan, R., Kavanagh, C., and Walker, G.: Insight into the composition, morphology, and formation of the calcareous shell of the serpulid hydroides dianthus, J. Struct. Biol., 169, S5-S20, 2010.

Wang, R. Z., Addadi, L., and Weiner, S.: Design strategies of sea urchin teeth: structure, composition and micromechanical relations to function, Philos. T. R. Soc. B, 352, 46-480, 1997.
Weiner, S., Addadi, L., and Wagner, H. D.: Materials design in biology, Mater. Sci. Eng., 11, 1-8, 2000.

Zienkiewicz, O., Taylor, Z., and Zhu, J.: The finite element method: its basis and fundamentals, Butterworth-Heinemann, Amsterdam, 1-753, 2005. 